DOI: $10.36732 /$ riep.v1i3.38

\title{
PROFISSÃO DOCENTE EM CONTEXTO DE DIVERSIDADE: CARTOGRAFIAS DAS PESQUISAS EM GÊNERO E SEXUALIDADE NA BAHIA
}

\section{Diversity Teacher Profession: cartographs of gender and sexuality research in Bahia}

\author{
Ana Lúcia Gomes da Silva ${ }^{1}$ \\ Fernando Macedo da Silva ${ }^{2}$ \\ Diego Silva Leite ${ }^{3}$
}

\begin{abstract}
Resumo: Este estudo toma como centralidade a interseccionalidade de gênero, sexualidades e raça/etnia, sob as lentes da interseccionalidade como uma ferramenta necessária para pensar a problemática desses marcadores sociais da diferença nas abordagens em sala de aula. 0 objetivo central do estudo é cartografar as pesquisas que abordem essa temática, no período de 20072018. Objetivou ainda mapear os anos de produção destas pesquisas, instituições de produção, sexo dos pesquisadores, perspectivas da diversidade tomadas pelos pesquisadores. 0 método adotado foi a pesquisa bibliográfica com ênfase na revisão sistemática, tendo como inspiração as contribuiç̃̃es da cartografia social. Para o levantamento de dados, foram analisadas as produções de pesquisas de mestrado e doutorado, desenvolvidas em Programas de Pósgraduação em educação de universidades da Bahia, a fim de levantar as contribuições dos estudos quanto às dimensões de gênero e sexualidade. 0 estudo apontou a necessidade da centralidade da diversidade no processo educacional de formação humana emancipatório, que tem marcado os projetos educativos da universidade, cuja tônica está no trabalho que prioriza a parceria entre Universidade e Educação Básica, numa perspectiva colaborativa.
\end{abstract}

Palavras-chave: Profissão docente. Interseccionalidade. Educação Básica . Cartografia.

\begin{abstract}
This study focuses on the intersectionality of gender, sexuality and race/ethnicity, under the lens of intersectionality as a necessary tool for thinking about the problem of these social markers of difference in classroom approaches. The main objective of the study is to map the researches that address this theme, in the period 2007-2018. It also aimed to map the years of production of these researches, production institutions, gender of researchers, perspectives of diversity taken by researchers. The adopted method was the bibliographic research with emphasis on the systematic review, having as inspiration the contributions of the social cartography. For data collection, we analyzed the master's and doctoral research productions, developed in postgraduate programs in education of universities in Bahia, in order to raise the contributions of the studies regarding the dimensions of gender and sexuality. The study pointed to the need for the centrality of diversity in the educational process of emancipatory human formation, which has marked the university's educational projects, whose emphasis is on the work that prioritizes the partnership between University and Basic Education, in a collaborative perspective.
\end{abstract}

Keywords: Teaching profession. Intersectionality. Basic education. Cartography

\footnotetext{
${ }^{1}$ Pós-doutora em Educação pela Universidade Federal do Triângulo Mineiro-UFTM. Docente permanente do Programa de Pós-Graduação em Educação e Diversidade (PPED). Líder do Grupo de Pesquisa Diversidade, Formação, Educação Básica e Discursos - DIFEBA (UNEB). Lattes: <http://lattes.cnpq.br/2930871385446150 Orcid: http://orcid.org/0000-0002-3880-3322.

${ }^{2}$ Licenciado em Letras - Língua Portuguesa e Literaturas pela Universidade do Estado da Bahia - DCH IV. Bolsista de Iniciação Científica entre os anos de 2016 a 2019. Membro do Grupo de Pesquisa Diversidade, Formação, Educação Básica e Discursos - (DIFEBA). Orcid: https://orcid.org/0000-0002-5662-749X.

${ }^{3}$ Graduando em História pela UNEB. Bolsista IC CNPq/Capes [2018-2019). Membro do Grupo de Pesquisa Diversidade, Formação, Educação Básica e Discursos - (DIFEBA). Orcid: https://orcid.org/0000-0002-2258-7880
}

Rev. Nova Paideia - Revista Interdisciplinar em Educação e Pesquisa, Brasília/DF, v. 1, n. 3, Núm. Esp. p. 43 - 55 - ANO 2019 


\section{Introdução:}

Este artigo se ancora no campo da educação e teve como tema mais amplo a discussão realizada na mesa-redonda intitulada "Desafios da educação e dos educadores na Agenda 2030 da ONU” na IV Jornada Ibero-Americana de Pesquisas em Políticas Educacionais e Experiências Interdisciplinares na Educação (IV JORNEDUC) que objetivou compartilhar uma maior consciência e compromisso junto aos participantes do evento e contribuir para promover no Brasil o 4o objetivo da Agenda 2030 da ONU, refletindo sobre a importância de um desenvolvimento voltado para a redução das desigualdades e para a concretização dos Objetivos do Desenvolvimento Sustentável da Agenda 2030 das Nações Unidas.

0 recorte realizado pelos autores neste artigo toma como centralidade para o debate, o diálogo com o objetivo 4 do desenvolvimento sustentável que visa "Assegurar a educação inclusiva e equitativa de qualidade, e promover oportunidades de aprendizagem ao longo da vida para todos. A meta 4.1 em especial a ser atingida até 2030 busca assegurar "que todas as meninas e meninos completem uma educação primária e secundária gratuita, equitativa e de qualidade, que conduza a resultados de aprendizagem relevantes e eficazes , considerando inclusão e equidade; igualdade de gênero". (UNESCO, 2016).

O presente estudo realizado está vinculado à pesquisa intitulada "Educação Básica no território do Piemonte da Diamantina: formação, contextos de diversidade e práticas pedagógicas" e nasce do diálogo entre bolsistas e orientadora considerando a necessidade de realizar o desdobramento dos estudos já realizados ${ }^{4}$. Na interface com a diversidade, toma como objeto de estudo gênero e sexualidade nas pesquisas com o tema diversidade e profissão docente no estado da Bahia entre os anos de 2007 a 2018. É necessário destacar ainda que este estudo faz parte de uma pesquisa mais ampla, intitulada, "Profissão Docente na Educação Básica da Bahia" desenvolvida pelos grupos Docência, Narrativas e Diversidade na Educação Básica - DIVERSO, vinculado ao Programa de PósGraduação em Educação e Contemporaneidade - PPGEduC da Universidade do Estado da Bahia - UNEB e Diversidade, Formação, Educação Básica e Discursos - DIFEBA, vinculado ao Programa de Pós-Graduação em Educação e Diversidade - MPED da UNEB, campus IV Jacobina.

A pesquisa tem objetivo central cartografar as pesquisas cujo objeto de estudo é a diversidade na interface com a profissão docente, destacando neste texto as dimensões de gênero sexualidade e raça, este último, considerando os dados baianos apresentados pelo IBGE, buscando responder à questão que nos move: Quais as principais contribuições das pesquisas analisadas para a profissão docente no campo da diversidade e as dimensões de gênero e sexualidade? Objetivamos ainda neste artigo mapear os anos de

\footnotetext{
${ }^{4}$ Pesquisa 1 intitulada: "Práticas pedagógicas na Educação Básica de Jacobina - BA em contextos de diversidade: Interseccionalidade e recursos multimídias”. Edital 026/2018. Teve fomento de Fundação de Amparo a Pesquisa do Estado da Bahia- FAPESB. Pesquisa 2-Intersecção da identidade de gênero e sexualidades das mulheres do campo. Também Bolsista Fapesb no mesmo edital público.
} 
produção destas pesquisas, instituições de produção, sexo dos pesquisadores, perspectivas da diversidade tomadas pelos pesquisadores a fim de compreender como a intersecção de gênero e sexualidade tem contribuído e desafiado a profissão docente, considerando neste bojo os desafios e implicações para as práticas pedagógicas.

Tomamos a cartografia com inspiração metodológica e utilizamos a pesquisa bibliográfica com ênfase na revisão sistemática, considerando os estudos já produzidos acerca da importância da revisão sistemática. Segundo (MC; RF, 2007, p. 1), a revisão sistemática trata-se de estudo que se caracteriza como metódico que serve para nortear projetos e indicar novas possibilidades investigativas no campo da ciência.

Com base nos procedimentos elencados por Galvão e Pereira (2014, p.183) para a elaboração da revisão sistemática, dentre eles - pergunta de pesquisa, busca, seleção, extração de dados, avaliação e análise - foram realizadas cartografias das produções de pesquisas de mestrado e doutorado, desenvolvidas em Programas de Pós-graduação em educação de universidades da Bahia, a fim de levantar as contribuições dos estudos quanto às dimensões de gênero e sexualidade. Para fins de organização, dividimos o artigo nos seguintes tópicos: Breve histórico do conceito de interseccionalidade e sua interface com a educação; Cartografias em devir: dados da revisão sistemática e em seguida as (In) conclusões.

\section{Diversidade, interseccionalidade em interface com a educação:}

0 conceito de diversidade que tomamos para este estudo está ancorado na perspectiva dos estudos culturais, que tomam a diversidade, a identidade e a diferença como fatos sociais, os quais são resultados da diferença, tomada como processo. $\mathrm{Na}$ perspectiva de Silva (2000)

A identidade e a diferença têm que ser ativamente produzidas. Elas não
são criaturas do mundo natural ou de um mundo transcendental, mas do
mundo cultural e social. Somos nós que as fabricamos, no contexto de
relações culturais e sociais. A identidade e a diferença são criações sociais
e culturais. (SILVA, p. 76)

Para tanto neste texto procuramos compreender a interface da diversidade na educação por meio das pesquisas levantadas, pois consideramos que debater acerca das dimensões de gênero e sexualidade no cenário da educação básica, que é marcado pela dinamicidade e pluralidades dos sujeitos que o ocupam, e que "que os saberes docentes são temporais, plurais, e heterogêneos, personalizados e situados e, ainda, carregam consigo as marcas do seu objeto, que é o ser humano" (XAVIER, 2014, p. 831). Implica reconhecer que as identidades e diferenças que são produzidas através destas relações e que estão intrinsicamente relacionadas aos contextos da profissão docente, construindo saberes e ressignificando os sujeitos.

A interseccionalidade, termo cunhado pela intelectual afro-estadunidense Kimberlé Crenshaw entre os anos de 1960 e 1970, época em que o movimento feminista 
negro passava por tensões e o movimento feminista radical havia se desenvolvido. Estes movimentos contribuíram para a compreensão de que o gênero "foi o principal fator determinante no destino de uma mulher" (HOOKS, 2015).

O movimento contestou a noção de que as mulheres fossem uma categoria homogênea, o argumento principal era o de que as mulheres brancas não serviam como parâmetro para uma representação precisa do feminismo como um todo. A partir do momento em que se reconheceu que as diversas formas de opressão vividas pelas mulheres brancas e de classe média eram diferentes das vividas pelas mulheres negras, pobres e com deficiências, as feministas então procuraram compreender como gênero, raça e classe somados eram responsáveis por operar mecanismos de opressão.

Assim, a interseccionalidade constitui-se como uma potente ferramenta para problematizar as relações e os elos existentes entre os diversos marcadores sociais da diferença como raça, sexo, gênero, classe etc. ela age:

possibilitando-nos avançar em perspectiva e prática de problematização rizomática de "uma teoria transdisciplinar visando apreender a complexidade das identidades e das desigualdades sociais, através de uma abordagem integrada Ela [a interseccionalidade] refuta a partição e a hierarquização dos grandes eixos de diferenciação social [...]" (BILGE 2009 apud POCAHY, 2011, p. 19-20)

Destarte, cabe assim, acrescentar que a preocupação não está no simples reconhecimento dos múltiplos sistemas de opressão que operam amparados por estes marcadores, mas justamente no desafio de compreender a complexidade das relações estabelecidas nas identidades e diferenças.

A diversidade é ancorada na diferença que nos marca. Analisar a diversidade como construção histórica, social, cultural e política nos faz refletir sobre os papeis desenvolvidos pelos agentes dessa construção. Esses agentes são a identidade e a diferença. Segundo Tomaz Tadeu Silva (2000) "a identidade é a referência, é o ponto original relativamente ao qual se define a diferença." Ou seja, a identidade é o que o sujeito é, o que define a diferença é o que o outro sujeito é, para nós é a marca, uma diferença que se produz em nossas formas-sujeitos, formas de ser. A identidade e a diferença estão estreitamente conectadas com relações de poder, em um campo de disputas. Segundo Tomaz Tadeu (2000) a identidade e diferença não são, nunca, inocentes. A diferenciação é o processo central pelo qual a identidade e a diferença são produzidas. Esses papéis confluídos são resultados de produções simbólicas, diferença como singularidade, produção de si mesmo, sempre em devir. Essas produções são legitimadas pelas relações de poder e desigualdades de várias ordens. Na perspectiva de Silva (2000):

A identidade e a diferença têm que ser ativamente produzidas. Elas não são criaturas do mundo natural ou de um mundo transcendental, mas do mundo cultural e social. Somos nós que as fabricamos, no contexto de relações culturais e sociais. A identidade e a diferença são criações sociais e culturais. (SILVA, p. 76) 
Gênero e sexo são categorias socialmente construídas que expressam relações de poder. Os papéis de homem e mulher provêm de significados, estabelecendo hierarquias entre homens e mulheres resultando em posições assimétricas dentro da sociedade. Para Foucault os gêneros se produzem nas relações de poder. Essas relações de poder produzem sujeitos, fabricam corpos dóceis, induz comportamentos, "aumenta a utilidade econômica" e "diminui a força política" dos indivíduos (MACHADO, 1993, p. XVI).

O sujeito é marcado dentro do âmbito da diversidade, e essas demarcações fundidas entre a identidade e a diferença fazem emergir diferenças entres os sujeitos. Uma desses marcadores abordadas no presente artigo estão em torno do gênero e da sexualidade. Discursos sobre gênero de algum modo incluem ou englobam as questões de sexualidade (MAC NA GHAILL, 1996). Existem várias formas de sexualidade e de gênero, ambas são interdependentes, ou seja, afetam umas às outras.

Stuart Hall (1992, p.4) afirma que o gênero institui a identidade do sujeito, sendo o gênero parte desse sujeito e não o sujeito. 0 sujeito é composto por identidades plurais, assim pertencentes a diferentes grupos sexuais, de gênero, classe, etnia etc. A identidade sexual e de gênero estão profundamente inter-relacionadas, contudo não são a mesma coisa. Ambas são sempre construídas, instáveis, passíveis de transformações.

A construção social, dos gêneros e da sexualidade de homens e mulheres fazem parte, segundo Deborah Britzman (1996) dos "marcadores sociais". A princípio a diferença entre os gêneros serviu para explicar e justificar as mais variadas distinções entre mulheres e homens. Essas diferenças foram demarcadas pelas relações de poder. É importante salientar, que esse poder é ou era hegemonicamente masculino e patriarcal. Segundo Robert Connell (1995, p. 190) há uma "narrativa convencional" sobre a maneira como as masculinidades são construídas, e que supõe, por essa narrativa, que "toda cultura tem uma definição da conduta e dos sentimentos apropriados para os homens". Aprender essa conduta significa que meninos se afastariam do comportamento das mulheres. Connell pensa na construção da masculinidade como um "projeto" - tanto no coletivo quanto no individual. É esta rede de aprendizagens que as pesquisas contribuem para visibilizar e oportunizar o empoderamento das mulheres.

\section{Cartografias em devir: dados do cenário baiano}

Neste estudo buscamos realizar uma cartografia das pesquisas realizadas no estado da Bahia de 2007 a 2018 em nível de mestrado e doutorado, utilizando o método cartográfico proposto por Deleuze e Guattari, ao apontarem que a cartografia se compromete a indagar as complexidades da pesquisa:

a cartografia se apresenta como valiosa ferramenta de investigação, exatamente para abarcar a complexidade, zona de indeterminação que a acompanha, colocando problemas, investigando o coletivo de forças em cada situação, esforçando-se para não se curvar aos dogmas reducionistas. (ROMANGNOLI, 2009, p. 168) 
Este tipo de cartografia diferente da cartografia tradicional a qual como apontam Filho e Teti (2013) se preocupa em traçar mapas de territórios, regiões, fronteiras e demais demarcações assim como demais aspectos geográficos, podendo também tratar da distribuição de uma população em um determinado espaço, mostrando suas características étnicas, sociais, econômicas, de saúde, moradia etc. Ana Lúcia Silva et al. (2018). Na cartografia social como apontado por Lima e Costa (2012) a importância está no significado do objeto e não no desenho mapeado, considerando que as relações, as subjetividades, contextos e interações relacionais do sujeito que mapeia o espaço vivido propicia o mapeamento de conceitos sociais como conflitos, histórias de vida, prática de trabalho etc.

Desta feita, consideramos que o método cartográfico possui para nosso estudo essa valiosa contribuição, pois nos permite analisar essas subjetividades e complexidades neste conjunto de pesquisas levantadas, nos permitindo analisá-las quanto as suas especificações: ano de pesquisa, instituição, metodologia, método, gênero do pesquisador e perspectiva da diversidade. Abordaremos a seguir a revisão sistemática realizada.

\section{Revisão sistemática: os dados emergentes}

A revisão sistemática foi realizada entre os meses de novembro 2018 a março 2019, no Catálogo de Teses e Dissertações da Capes e Biblioteca Digital Brasileira de Teses e Dissertações (BDTD), buscando mapear as pesquisas num recorte temporal compreendido entre 2007 e 2018, com os descritores profissão docente e diversidade, focando nas pesquisas produzidas no estado da Bahia, abordando as dimensões da diversidade, entre elas gênero e sexualidade as quais iremos nos ater neste estudo.

Foram cartografadas 08 pesquisas, das quais é possível delinear um cenário marcado pela produção feminina, uma vez que esta representa $75 \%$ destas pesquisas, ou seja, 06 pesquisas:

Gráfico 1 - Sexo das pesquisadoras

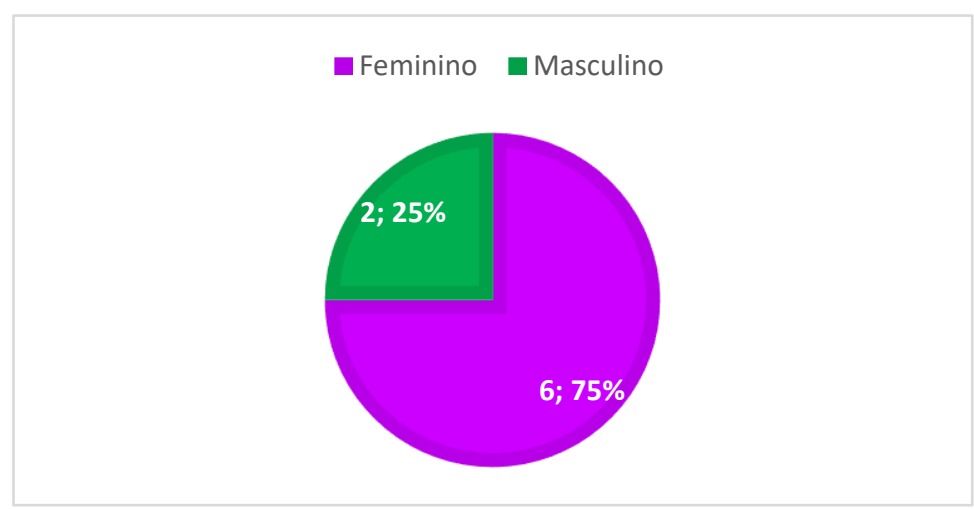

Fonte: Elaborado pelos autores (2019) 
Em relação aos anos de produção destes estudos percebemos que a maioria deles foram produzidos nos dois anos iniciais do recorte temporal 2007 e 2008, com duas pesquisas cada, representando assim 58\%, cuja descontinuidade se apresenta nos anos seguintes com percentuais abaixo de $3 \%$.

Gráfico 2 - Quantitativo da produção no período de 2007-2018

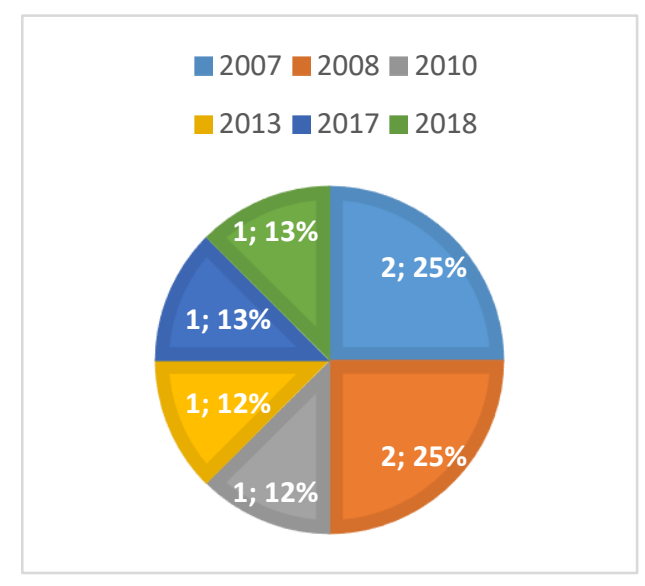

Fonte: Elaborado pelos autores (2019)

Em relação às instituições de produção destas pesquisas, a Universidade Federal da Bahia (UFBA) desponta com a metade da produção destas pesquisas. Este dado ratifica que as instituições com maior longevidade e tradição na pesquisa são as que mais se destacam, neste caso da Bahia, a UFBA, como uma instituição histórica e relevante com setenta anos (70), completados em 20 de setembro de 2019.

Gráfico 3: Quantidade de produção por IES

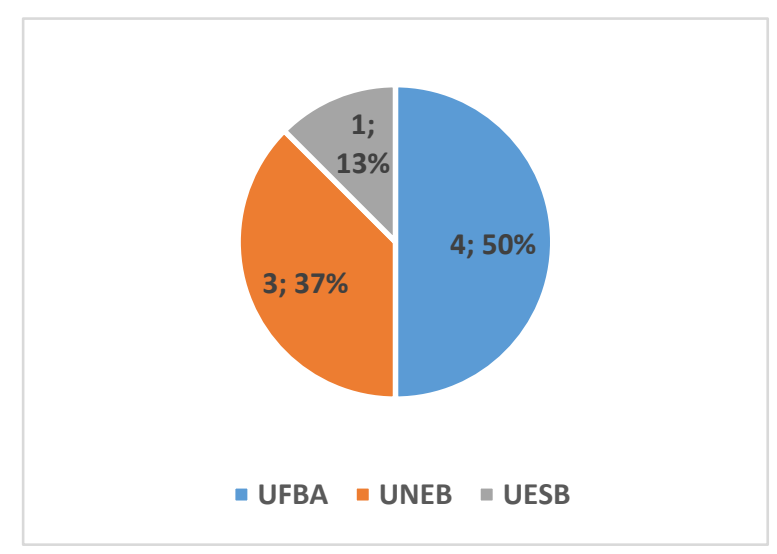

Fonte: elaboração dos autores (2019)

No que diz respeito à dimensão de gênero, foram, encontradas 06 (pesquisas) pesquisas - estabelecendo relação com a formação/profissão docente -, e esteve relacionada à dimensão sexualidade em 01 (uma) pesquisa: "O Gênero e a Sexualidade na Escola: um estudo com docentes do Instituto de Educação Gastão Guimarães em Feira de Santana - BA", dissertação de Silvia Karla Almeida dos Santos (UNEB), onde são 
investigadas as formas de compreensão das identidades de gênero e da sexualidade no exercício da docência.

Considerando as perspectivas abordadas nas pesquisas, a dimensão gênero foi tratada como temática central em 04 (quatro) produções, a saber: Dissertação intitulada "Formação Docente e Concepção de Gênero: Um Estudo sobre Processos identitários de egressas da Faculdade de Educação da Bahia", produzida por Karina Nery Embirussu (UFBA); Tese "Cuidado, relações de gênero e trabalho docente na educação infantil: Um estudo de professoras e professores da pré-escola pública”, de Eronilda Maria Góis de Carvalho (UFBA); Dissertação "Identidades, Currículo e Formação Docente: Um estudo sobre implicações de gênero em Práticas Educativas de estudantes de Pedagogia" de autoria de Tatiane de Lucena Lima (UFBA); Dissertação intitulada "Sinais de gênero nas diferentes linguagens que tecem o discurso na escola”, de Rita de Cássia Costa Moreira (UFBA).

A dissertação "O Gênero e a Sexualidade na Escola: um estudo com docentes do Instituto de Educação Gastão Guimarães em Feira de Santana - BA", produzida por Sílvia Karla Almeida Dos Santos (UNEB); e, por fim, a dissertação "A presença do docente do gênero masculino no contexto de escolarização de crianças nos anos iniciais do ensino fundamental", de Anderson Santana de Souza (UESB). A tese de doutorado "Cuidados, relações de gênero e trabalho docente na educação infantil: um estudo de professoras e professores da pré-escola pública", publicada em 2007, pela UFBA, de autoria de Eronilda Maria Góis de Carvalho, discute a interpretação do trabalho docente na educação infantil, profissão caracterizada como feminina, problematizando as questões ligadas ao cuidado e às relações de gênero na esfera desse primeiro segmento da Educação Básica.

A dimensão sexualidade foi identificada em 03 (três) pesquisas, todas produzidas a nível de mestrado, sendo que a dimensão aparece interseccionalizada às demais dimensões como gênero, raça/etnia em 02 (duas) pesquisas, A pesquisa de Silvia Karla dos Santos já citada anteriormente, e a pesquisa de Joana Maria Leoncio Nuñez (2018), intitulada "Nas teias da Diversidade: experiências (auto)formativas dos(as) Professores(as) Supervisores(as) do PIBID/ UNEB". A sexualidade aparece tratada de forma isolada em apenas 01 (uma) sendo esta intitulada "As práticas pedagógicas para a diversidade sexual nas escolas estaduais de Vitória da Conquista - BA" de autoria de José Miranda de Oliveira Junior (2017).

0 total de pesquisas realizadas apontaram 02 elaboradas por mulheres e 01 produzida por homens nas seguintes instituições baianas: UNEB (02), UESB (01), destacando a primeira com maior número de trabalhos. Em relação ao período de produção, a primeira pesquisa emergiu em 2010, no período de 2011 a 2016 não foram encontradas pesquisas, apenas em 2017 foi encontrada 01 pesquisa e novamente em 2018 (01 pesquisa). 0 destaque para a Universidade do Estado da Bahia com maior número de pesquisas ratifica a função estratégica da UNEB com implantação de 
programas de pós-graduação no interior baiano ${ }^{5}$ que tratam das questões da educação e diversidade, como por exemplo, o Programa de Pós-Graduação em Educação e Diversidade (PPED) no campus IV Jacobina, cuja primeira turma defendeu suas pesquisas em $2016^{6}$.

Percebemos que estas pesquisas ao abordar as questões de gênero e sexualidade implicadas com a profissão docente, tomam as questões a partir da problematização das concepções de gênero, dos papeis de gênero, da sexualidade entendida como diversa e da necessidade de reinvenção das práticas pedagógicas como forma de ressignificar os papeis de gênero, estigmas e preconceitos perpassando a formação e o exercício da docência.

As pesquisas que abordam as dimensões interseccionalizadas entre si e demais marcadores como raça/etnia e classe ampliam o debate de modo relevante, pois é constatável a preocupação com novas práticas de formação e construção do conhecimento de modo a romper com as hierarquizações das formas de opressão. Pensemos então que, estes professores pesquisadores que buscam e apontam novos caminhos para o saber contribuem para reverter práticas hegemônicas e excludentes e na reversão de formas de opressão, construindo cenários possíveis de entender a diversidade e a diferença como naturais, desnaturalizando o machismo, a homofobia, racismo e todas as formas de opressão.

Outro dado relevante que dialoga com a pesquisa diz respeito ao modo como estas pesquisas desenvolvidas se voltam para a parceria entre universidade e educação básica e visa o fortalecimento de políticas afirmativas que incluam os sujeitos em sua singularidade, sua diferença, quer quanto à sua sexualidade, expressando com seus corpos seu modos de estar no mundo. Como exemplo da visibilização destes dados para combater a discriminação com as distintas expressões da sexualidade e das diferenças apresentadas pelos marcadores de gênero, raça, classe social, hoje, na Universidade do Estado da Bahia são contemplados com reserva de sobrevagas quilombolas; ciganos; pessoas com deficiência, transtorno do espectro autista e altas habilidades; transexuais, travestis e transgêneros, reafirmando o caráter popular, inclusivo e socialmente referenciado da UNEB. Esta ação foi aprovada através da RESOLUÇÃO № 1.339/2018.7

Amplia ainda esta ação no âmbito das políticas afirmativas a interiorização da pósgraduação stricto sensu, os cursos de mestrado e doutorado, e a internacionalização das

\footnotetext{
${ }^{5}$ A UNEB está territorializada em 24 campi universitários e 29 Departamentos, distribuídos por todo o Estado da Bahia. Por sua característica de multicampia, se interiorizou, fazendo com que segmentos mais vulneráveis pudessem acessar a universidade pública e de qualidade.

${ }^{6}$ Para aprofundamento ver: http://www.mped.uneb.br/. Acesso em 20 out.2019.

${ }^{7}$ Resolução publicada no D.0.E. 28-07-2018. Aprova o sistema de reservas de vagas para negros e sobrevagas para indígenas; quilombolas; ciganos; pessoas com deficiência, transtorno do espectro autista e altas habilidades; transexuais, travestis e transgênero, no âmbito da UNEB, e dá outras providências.Disponível em: https://portal.uneb.br/proaf/wpcontent/uploads/sites/65/2018/12/Res_1.339_2018consu-_-Res_reserva-de-vagas.docx.pdf. Acesso em 20 out.2019.
} 
suas iniciativas acadêmico-científicas também são pautas institucionais e estão em crescimento, sobretudo, desde a última década. Essas políticas, que se tornaram princípios institucionais, contribuíram decisivamente para o seu reconhecimento e legitimidade perante a sociedade baiana, que tem nesta Universidade uma referência de instituição comprometida com a formação cidadã e com o desenvolvimento humano e social.

Além dos dados da pesquisa é importante destacarmos que elas (des)velam e (re)velam os desafios tratados no tema da mesa-redonda da IV Jorneduc, já mencionado, considerando que os dados do estado da Bahia que apresentaremos a seguir, apontam de modo concreto como o cenário baiano é desafiador para a conquista da meta 4 da Unesco apresentada na introdução deste artigo, haja vista que o estado da Bahia teve o maior índice de desigualdade nos rendimentos do país. É o que aponta um levantamento que comparou dados de 2016 e 2017 e foi divulgado pelo Instituto Brasileiro de Geografia e Estatísticas (IBGE, 2018). Além do crescimento da desigualdade salarial, o estudo traz outras informações, como rendimento salarial familiar e aumento da renda de trabalho para homens, brancos e idosos e outros.

Com relação à liderança na desigualdade salarial, o IBGE aponta que de 2016 para 2017, o salário médio real dos trabalhadores que ganhavam menos na Bahia caiu 5,9\%, ao passar de $\mathrm{R} \$ 472$ para $\mathrm{R} \$ 444$. Entretanto, o rendimento médio de trabalho de $10 \%$ dos trabalhadores que detêm os maiores salários aumentou $31,7 \%$, passando de $\mathrm{R} \$ 5.946$ para R\$ 7.833. De acordo com a pesquisa do instituto, em 2017 na Bahia, 10\% de trabalhadores com maiores rendimentos ganhavam, em média, 18 vezes o salário da metade dos trabalhadores que ganhavam menos. Essa diferença foi de 13 vezes em 2016. No país, a distância permaneceu em 12 vezes de um ano para o outro.

A pesquisa do IBGE apontou, ainda, que na Bahia o aumento do rendimento efetivamente recebido por todos os trabalhos, entre 2016 e 2017, foi maior para os homens $(+17,2 \%)$ do que para as mulheres $(+6,2 \%)$; para os brancos $(+38,7 \%)$ do que para os pardos $(+5,7 \%)$ e pretos $(-1,6 \%)$. Esse aumento de renda, segundo o IBGE, acentuou algumas desigualdades já existentes, sobretudo por sexo e cor ou raça, objeto do nosso estudo, que na mirada da lente interseccional apontam opressões estruturais que se entrecruzam, nos dados sobre as mulheres, sobretudo as negras.

Ainda segundo a pesquisa, se em 2016 as mulheres baianas que trabalhavam recebiam, em média, o equivalente a $85 \%$ do salário dos homens, um ano depois passaram a receber $77 \%$. Em 2016, o rendimento médio dos pardos era 73,1\%, comparado ao dos brancos e passou a 55,7\% em 2017; já o dos negros equivalia a 69\% dos brancos em 2016 e passou a representar, em média, menos da metade (48,9\%) em 2017.

Todo este quadro marcado por desigualdades sociais acirram as desigualdades educacionais e acirram a exclusão dos jovens baianos ao ingresso no ensino superior, haja vista estarem exatamente representados nestes índices e deles fazerem parte. Importa ainda destacarmos que no quesito da violência de gênero, a Bahia registrou 26 casos de 
feminicídio este ano de 2019, de janeiro até maio, segundo dados da Secretaria de Segurança Pública da Bahia (SSP-BA) ${ }^{8}$ repassados ao BNews. Ainda segundo o órgão, no mesmo período, ocorreram outros casos nos quais a mulher foi vítima. Foram 12.400 mulheres registraram queixas por ameaças, 6.100 lesões corporais, 143 tentativas de homicídio, 99 homicídios. No ano passado, foram registrados 49 casos de feminicídio. Do total, 22 aconteceu na capital baiana, o que significa quase a metade dos crimes. Ainda sobre dados referentes ao crime, 1.733 medidas protetivas estavam em vigor no estado. Pesquisa realizada pelo Instituto Ibope (2004), constatou que $81 \%$ dos entrevistados apontaram, em respostas múltiplas, o uso de bebidas alcoólicas como o fator que mais provoca a agressão dos homens contra as mulheres (78\% dos homens).

\section{(In)conclusões}

Os resultados apontam que os desafios para a educação com qualidade social, includente e democrática, exige das políticas públicas revestida vontade política, assim como exige de pesquisadores/as implicados e engajados com a causa da educação, ao tomarem a realidade como ponto de partida-chegada em seus estudos investigativos, visando alterar a realidade pesquisada. Para tanto, destacamos o rigor epistêmico e metodológico nas pesquisas que fazemos, a posição política clara em defesa do combate às desigualdades educacionais, a postura ética como atitude, em defesa da vida humana, a inventividade ao investigar os fenômenos em distintos territórios habitados pelos/as pesquisadores/as , a despeito dos inúmeros desafios inerentes a um estado marcado por assimetrias regionais e por vulnerabilidade social. Este dado requer políticas educacionais inclusivas cada vez mais robustas e ampliadas. Neste sentido as universidades baianas têm contribuído nesta seara, em especial a Uneb, por seu alcance em inúmeras cidades do interior do estado da Bahia, que, com os resultados de pesquisas de intervenção, assim como através de programas e ações extensionistas, entre outras, voltados para a redução das desigualdades sociais em um estado estruturalmente desigual, como os índices econômicos e sociais bem revelam, os quais apresentamos neste estudo, renova e esperança na luta, em especial neste contexto sombrio, marcado por perdas de direito e retrocessos nas políticas que tratam da diversidade.

Percebemos ainda nas pesquisadas analisadas que a interseccionalidade aparece oferecendo suporte analítico e de reflexão para pensar a sobreposição dos diversos marcadores da diferença tendo na educação uma importante aliada para a deslegitimação de discursos e práticas que oprimem e estigmatizam os sujeitos que não fazem parte do padrão, da norma instituídos a partir das relações de poder pelas quais os mecanismos opressores são sustados.

A Bahia tem a tarefa desafiadora de contribuir para romper com as hierarquizações das formas de opressão. Estes e estas professores/as pesquisadores/as buscam e apontam novos caminhos para o saber, contribuem para reverter práticas hegemônicas e excludentes, bem como na reversão de distintas formas de opressão,

\footnotetext{
${ }^{8}$ Os dados ainda não estão atualizados pelo órgão, e o número deve aumentar segundo Secretaria de Segurança Pública da Bahia. Ver: http://www.mulheres.ba.gov.br/2019/08/2533/Secretaria-deSeguranca-Publica-assina-termo-de-combate-a-violencia-contra-mulher.html
} 
construindo redes, criando estratégias para dar visibilidade as pesquisas realizadas, de modo a promover o debate e contribuir para educar mulheres e homens na perspectiva da equidade de gênero e empoderamento feminino.

\section{REFERÊNCIAS}

AKOTIRENE, Carla. 0 que é interseccionalidade? Belo Horizonte-MG: Letramento: Justificando, 2018.

GALVÃO, T. F; PEREIRA, M. G. Revisões sistemáticas da literatura: passos para sua elaboração. Epidemiologia e Serviços de Saúde, v. 23, p. 183-184, 2014. Disponível em:< https://www.scielosp.org/scielo.php?pid=S2237-

96222014000100183\&script=sci_arttext\&tlng=es>. Acesso em: 04, out., 2018.

IV JORNADA IBERO AMERCICANA EM EDUCAÇÃO. Pesquisas em Políticas Educacionais e Experiências Interdisciplinares na Educação. Disponível em:

https://www.even3.com.br/ivjorneduc/. Acesso em 20 out. 2019.

INSTITUTO BRASILEIRO DE OPINIÃO E ESTATÍSTICA.

http://www.ibope.com.br/.Acesso em: 20. out. 2019.

INTITUITO BRASILEIRO DE GEOGRAFIA E ESTATÍTICA. (2018). https://www.ibge.gov.br/ Acesso em : 20. out. 2019.

LIMA, M.; COSTA, S. Cartografia social das crianças e adolescentes ribeirinhas/quilombolas da Amazônia. Revista Geografares, n. 12, p. 76-113, julho, 2012.

MAC NA GHAILL, M. “Deconstructing heterosexualities within school arenas”. Curriculum Studies. Vol. 4(2), 1996.

MACHADO, R. "Por uma genealogia do poder - Introdução". In: FOUCAULT, M. microfísica do poder. 11. Ed. Rio de Janeiro: Graal, 1993.

MANCINI, M.C; Sampaio, R. F. Estudos de revisão sistemática: um guia para síntese criteriosa da evidência científica. Revista brasileira de fisioterapia, v. 11, n. 1, p. 83-89, 2007. Disponível em: < http://www.scielo.br/pdf/\%0D/rbfis/v11n1/12.pdf> Acesso em: 04, out., 2018.

UNESCO. http://www.unesco.org/new/pt/brasilia/about-this-office/singleview/news/education_2030_incheon_declaration_and_and_framework_for_ac/.Acesso em 03.set.2019.

RODRIGUES, Gelberton VIEIRA; PORCHAT. Patrícia. Deborah Britzman e a educação sexual: entre a pedagogia queer e a psicanálise. Revista de Ciências Humanas, 
Florianópolis, v. 52, 2018, e56716 ISSN 2178-4582. http://dx.doi.org/10.5007/21784582.2018 .56716

ROMAGNOLI, Roberta C. A Cartografia e a relação pesquisa e vida. Psicologia e Sociedade, v. 21, n. 2, p. 166-173, 2009.

SILVA, Tomaz Tadeu. A produção social da identidade e da diferença. In: SILVA, Tomaz Tadeu (org. e trad.). Identidade e diferença: a perspectiva dos estudos culturais. Petrópolis: Vozes, 2000. p. 73-102.

SECRETARIA DE SEGURANÇA PÚBLICA DO ESTADO DA BAHIA. http://www.mulheres.ba.gov.br/. Acesso: em 20 out. 2019.

POCAHY, Altair. F. Interseccionalidade e educação: cartografias de uma prática conceito feminista. Textura, Canoas, n.23, p.18-30, jan./jun. 2011. 